\section{Kidney \\ Blood Pressure Research}

\title{
The Association of Klotho Polymorphism with Disease Progression and Mortality in IgA Nephropathy
}

\author{
Gang Jee Ko Eun Ah Lee $^{\mathrm{a}}$ Un Sil Jeon ${ }^{\mathrm{a}}$ Heui Jung Pyo ${ }^{\mathrm{a}}$ Ho Jun Chin ${ }^{\mathrm{b}}$ \\ Dong Wan Chae ${ }^{b}$ Suhnggwon Kim ${ }^{b}$ Young Joo Kwon ${ }^{a}$ \\ aKorea University Medical school, Department of Internal Medicine, bSeoul National University Bundang \\ Hospital
}

\section{Key Words}

IgA nephropathy • Polymorphism • Klotho gene

\begin{abstract}
Backgrounds: IgA nephropathy (IgAN) is the most common primary glomerulonephritis causing end stage renal disease (ESRD), and vasculopathy is known to involve disease progression. Klotho, a gene related to aging, has been reported to play a role in atherosclerosis and endothelial dysfunction. We investigated whether klotho gene polymorphism affect clinical course of IgAN. Methods: The data registered for PREMIER study which enrolled the patients with biopsy proven IgAN were analyzed. Two single nucleotide polymorphisms for klotho gene, G395A of promoter region and C1818T of exon 4, were examined, and investigated the association klotho genotypes with the progression of IgAN and patient survival. Results: Clinical data from 973 patients confirmed about survival were analyzed. The allele frequency was 0.830 and 0.170 for allele $G$ and $A$, and 0.816 and 0.184 for allele $C$ and $T$, which were complied with Hardy-Weinberg equilibrium $(p=0.996$ and 0.531 respectively). Death was observed more frequently in A-allele carriers of G395A polymorphism (0.7 vs $2.6 \%$, GG vs $\mathrm{GA}+\mathrm{AA}, \mathrm{p}=0.022$ ). Renal survival in Kaplan-Meier survival curve was also worse in same group $(p=0.04)$. Conclusion: Klotho gene polymorphism was associated with patient survival and disease progression of IgAN.
\end{abstract}

Copyright (C) 2012 S. Karger AG, Basel

\section{Introduction}

Klotho gene was discovered by Kuro-o et al as a gene related to suppression of aging process. It was demonstrated to have pleotropic functions that klotho mutant mice showed shortened life span, growth retardation, infertility, senile atrophy of the gonads, 


\section{Kidney \\ Blood Pressure Research}

Kidney Blood Press Res 2012;36:191-199

\begin{tabular}{l|l}
\hline DOI: $10.1159 / 000343408$ & (c) 2012 S. Karger AG, Basel
\end{tabular}

Published online: November 11, 2012

www.karger.com/kbr

Ko/Lee/Jeon et al.: The Role of Klotho Polymorphisms in IgA Nephropathy

arteriosclerosis, skin and muscle atrophy, osteoporosis, and emphysema resembling human aging process [1]. Klotho is predominantly expressed in distal tubule of kidney and choroid plexus of brain, and to lesser extent in reproductive and endocrine organ [1-2]. Klotho or its metabolites are considered to function as humoral factors because it shows multiple functions affecting various systems in spite of relatively limited distribution [3-4]. However, dominant expression of klotho in kidney suggested that klotho may have an important role in the pathogenesis of renal diseases, and the relationship of klotho with various renal diseases has been reported [5-7].

IgA nephropathy (IgAN) is the most common glomerulonephritis throughout the world especially in Far East and Southeast Asia comprising nearly half of all the patients with glomerular disease [8]. Up to $40 \%$ of patients with IgAN progress to end stage renal disease (ESRD) within 25 years, and IgAN accounts for 10\%-30\% of all cases of ESRD [9-10]. Although IgAN is considered as an immune complex disease with complement activation in mesangial cells due to IgA deposition [11], little has been known about the exact mechanisms. Endothelial dysfunction was known involve with the glomerular injury in IgAN [12-14], and the genetic factors were also suggested to contribute to the pathogenesis of IgAN that some genetic variations affected on the incidence and progression of IgAN [15-16]. Regarding the facts that klotho has been considered to implicate in atherosclerosis and endothelial dysfunction [17-20], and genetic variation of klotho has been reported to modulate the expression of klotho in tissue [21-22], we aimed to investigate the association of klotho gene polymorphisms with the progression and survival of IgAN patients in Korea.

\section{Materials and Methods}

\section{Study subjects}

We used the database of the Progressive Renal disease and Medical Informatics and gEnomics Research (PREMIER) program sponsored by the Korean Society of Nephrology (KSN) which enrolled the subjects aged 18yr or more with primary and secondary glomerulonephritis diagnosed by renal biopsy from 34 hospitals and clinics in Korea since August 2003. The clinical data and genomic DNA extracted from the peripheral blood of the patients were collected and shared. In 2010, the genomic data of 1,080 patients who were diagnosed with IgAN by renal biopsy from April 1988 to May 2007 were analyzed for our study. Patients with evidence of systemic disease such as chronic liver disease and systemic lupus erythematosus were excluded, and data of patients who were not confirmed about survival were also dropped. This study was approved by the Institutional Review Board in Korea University Kuro Hospital and other participated hospitals.

\section{Clinical data}

Database was made for the candidate patients by a qualified nurse who visited every participated institution to collect the clinical data at the time of renal biopsy and during follow-up visits. Clinical data were gathered such as age, gender, body mass index (BMI), history of diabetes, blood pressure, serum protein, albumin, cholesterol, uric acid, creatinine, hemoglobin, proteinuria by dipstick test, urine RBC measured by microscopic examination, and medication history related to hypertension including angiotensin II type I receptor blockers, HMG-CoA reductase inhibitors, and steroids. We calculated the estimated glomerular filtration rate (eGFR) by the modified modification of diet in renal disease (MDRD) equation. ESRD patients were defined as the patients who should start dialysis treatment, and follow-up duration for renal survival was defined as the time period between diagnosis with renal biopsy and initiation of renal replacement therapy or last follow-up date. ESRD data were obtained from the Korean ESRD registry, "Insan Memorial Dialysis Registry" of KSN. The registry contained the data of patients treated with renal replacement therapy from 1985 to 2008. The mortality data were obtained from the database of the Korean National Statistical Office (http://www.nso.go.kr). The mortality data available until December 2008 were collected. 


\section{Kidney Blood Pressure Research}

Klotho genotype assessment

The buffy coat was obtained from blood samples and then refrigerated at $-70^{\circ} \mathrm{C}$, and genomic DNA was extracted using QIAamp blood kits (Kyoto, Japan). The genotypings of G395A in the promoter region and C1818T in exon 4 were performed via an allelic discrimination assay with TaqMan probes (SCG, Seoul, Korea). The detector used in this experiment was an ABI Prism 7200 sequence detection platform (Perkin Elmer Applied Biosystems, Foster City, CA). The quality control of the machine was performed with regular background calibration and pure dye calibration. The primers and probes were used as follows.

(1) G-395A: Forward primer, TAGGGCCCGGCAGGAT; Reverse primer, CCTGGAGCGGCTTCGTC

(2) C1818T: Forward primer, CCAGCCCCAGATCGCTTTA; Reverse primer, GGCCCAGTCCAGGGAGAA

\section{Statistical assessment}

The statistical analysis was done by SPSS program (ver 12.0, Chicago, IL, USA). All results are expressed as means \pm standard deviation, and significance was defined as a $p$ value $<0.05$. Distribution of allele frequency was evaluated with Hardy-Weinberg equilibrium using the $\chi^{2}$ test. Independent t-test and chisquare test were used to compare differences between group according to genotypes or survival. Logistic regression analysis was performed to adjust for age, gender, and univariate risk factors for survival. Renal survival curves were prepared using the Kaplan-Meier method, and compared the cumulative incidence of case which required dialysis treatment by log-rank test.

\section{Results}

Clinical characteristics of study subjects

Nine hundred seventy three people were included in total. The general characteristics of the study population are shown in Table 1. The mean age was $37.0 \pm 13.7$ years, and the proportion of male patients was slightly larger than female (55.5\%). The mean BMI was $23.5 \pm 4.0$, and patients who were diagnosed diabetes were 31 (3.2\%). Mean follow-up period was $50.0 \pm 27.8$ months. In G395A single nucleotide polymorphism (SNP) of promoter region for klotho gene, 671 (68.9\%) had GG genotype, 274 (28.2\%) the GA genotype, and 28 (2.9\%) the AA genotype. In C1818T SNP, 645 (66.3\%) had CC genotype, $298(30.6 \%)$ the CT genotype, and $30(3.1 \%)$ the TT genotype. The allele frequency was 0.830 and 0.170 for allele $\mathrm{G}$ and $\mathrm{A}$, and 0.816 and 0.184 for allele $\mathrm{C}$ and $\mathrm{T}$, which were complied with Hardy-Weinberg equilibrium ( $\mathrm{p}=0.996$ and 0.531 respectively). For comparison between genotypes with G395A and C1818T polymorphisms, patients were divided by A allele into A allele carriers vs non-carriers (GA+AA vs GG), and by $\mathrm{T}$ allele into $\mathrm{T}$ allele carriers vs non-carriers (CT+TT vs CC). A and T allele carriers of both polymorphisms have been reported as genotypes with lower klotho expression. The proportion of patients who have history of hypertension at diagnosis was higher in A allele carriers (A allele carriers vs non-carriers 43.9 vs $35.8 \%$, $\mathrm{p}<0.05)$. However, systolic and diastolic blood pressure, and the number of medication for hypertension were not different between A allele carriers and non-carriers. Except that, there were no statistically significant differences in general characteristics among groups according to genotype.

\section{Association of genotypes with patient survival}

Thirteen patients were dead during follow-up period (1.3\%). The association of both SNPs with survival was analyzed (Table 2). There were no differences in survival between the different genotypes of C1818T polymorphism. As for G395A polymorphism, the A allele carriers showed higher mortality compared to non-carriers (A allele carriers vs non-carriers 2.6 vs $0.7 \%, \mathrm{p}=0.022$ ).

\section{Association of genotypes with renal survival}

The proportion of patients who should be treated with dialysis was not significantly different between genotypes of both polymorphisms (Table 3). However, upon the 


\section{Kidney Blood Pressure Research}

Kidney Blood Press Res 2012;36:191-199

\begin{tabular}{l|l}
\hline DOI: $10.1159 / 000343408$ & (c) 2012 S. Karger AG, Basel
\end{tabular}

Published online: November 11, 2012

www.karger.com/kbr

Table 1: Baseline characteristics of the study population ( $\mathrm{n}=973$ ) and comparison according to G395A and C1818T polymorphism genotypes

\begin{tabular}{|c|c|c|c|c|c|}
\hline & $\begin{array}{c}\text { Total } \\
(\mathrm{n}=973)\end{array}$ & $\begin{array}{c}\mathrm{GG} \\
(\mathrm{n}=671)\end{array}$ & $\begin{array}{c}\mathrm{GA}+\mathrm{AA} \\
(\mathrm{n}=302)\end{array}$ & $\begin{array}{c}C C \\
(n=645)\end{array}$ & $\begin{array}{c}\mathrm{CT}+\mathrm{TT} \\
(\mathrm{n}=328)\end{array}$ \\
\hline & & $671(70 \%)$ & $302(30 \%)$ & $645(66.3 \%)$ & $328(33.2 \%)$ \\
\hline Age (yrs) & $37.0 \pm 13.7$ & $36.5 \pm 13.5$ & $37.7 \pm 15.1$ & $36.9 \pm 13.7$ & $37.1 \pm 14.6$ \\
\hline Sex (male \%) & $540(55.5 \%)$ & 367 (54.6\%) & 173 (57.1\%) & $351(54.2 \%)$ & 189 (57.7\%) \\
\hline BMI & $23.5 \pm 4.0$ & $23.3 \pm 4.0$ & $23.7 \pm 3.9$ & $23.5 \pm 4.1$ & $23.4 \pm 3.9$ \\
\hline Follow-up periods (m) & $50.0 \pm 27.8$ & $51.1 \pm 28.0$ & $48.2 \pm 26.8$ & $50.2 \pm 26.8$ & $50.3 \pm 29.3$ \\
\hline History of DM (\%) & $31(3.2)$ & $21(3.1)$ & $10(3.2)$ & $23(3.6)$ & $8(2.5)$ \\
\hline History of HTN (\%) & $373(38.4)$ & $240(35.8)$ & $133(43.9)^{*}$ & $245(37.9)$ & $128(39.2)$ \\
\hline \multicolumn{6}{|l|}{ Medication (\%) } \\
\hline ACEi or ARB & $545(56.0)$ & $388(57.8)$ & 157 (51.9) & 369 (57.1) & $176(53.8)$ \\
\hline Steroid & $112(11.5)$ & $78(11.6)$ & $34(11.1)$ & $73(11.2)$ & $39(11.9)$ \\
\hline HMG-CoA reductase & $160(16.4)$ & $106(15.7)$ & $54(17.8)$ & $100(15.4)$ & $60(18.3)$ \\
\hline Systolic / diastolic blood & $125.0 \pm 17.7 /$ & $124.3 \pm 18.4 /$ & $126.7 \pm 16.7 /$ & $125.1 \pm 18.5 /$ & $124.9 \pm 16.7 /$ \\
\hline pressure $(\mathrm{mmHg})$ & $78.0 \pm 12.2$ & $77.5 \pm 12.7$ & $79.2 \pm 11.3$ & $77.9 \pm 12.9$ & $78.3 \pm 10.9$ \\
\hline $\mathrm{Hgb}(\mathrm{g} / \mathrm{dL})$ & $13.9 \pm 2.0$ & $13.0 \pm 2.0$ & $12.9 \pm 1.9$ & $13.0 \pm 2.0$ & $12.9 \pm 1.9$ \\
\hline Albumin (g/dL) & $3.8 \pm 0.6$ & $3.8 \pm 0.6$ & $3.8 \pm 0.7$ & $3.8 \pm 0.6$ & $3.8 \pm 0.7$ \\
\hline Total cholesterol (mg/dL) & $190.1 \pm 16.0$ & $188.9 \pm 62.6$ & $193.4 \pm 73.6$ & $189.4 \pm 60.0$ & $192.4 \pm 78.0$ \\
\hline Uric acid (mg/dL) & $6.1 \pm 1.9$ & $6.0 \pm 1.8$ & $6.3 \pm 2.1$ & $6.1 \pm 1.9$ & $6.1 \pm 2.0$ \\
\hline Creatinine $(\mathrm{mg} / \mathrm{dL})$ & $1.34 \pm 1.36$ & $1.35 \pm 1.48$ & $1.34 \pm 1.08$ & $1.38 \pm 1.40$ & $1.31 \pm 1.29$ \\
\hline $\mathrm{eGFR}\left(\mathrm{ml} / \mathrm{min} / 1.73 \mathrm{~m}^{2}\right)$ & $78.2 \pm 48.7$ & $76.5 \pm 32.6$ & $81.2 \pm 70.9$ & $79.1 \pm 54.2$ & $75.7 \pm 34.6$ \\
\hline Proteinuria>3+ (\%) & $173(17.8)$ & $115(17.1)$ & $58(18.9)$ & $111(17.1)$ & $62(18.8)$ \\
\hline Hematuria (\%) & 729 (74.9) & $513(76.5)$ & $216(71.4)$ & $493(76.4)$ & 236 (71.9) \\
\hline
\end{tabular}

Data are expressed as number of cases (percentage, $\%$ ) or mean \pm standard deviation (SD). $P$-values were obtained by the Pearson Chi-squared test for categorical variables, and the independent twosample t-test for numerical variables. ${ }^{*} \mathrm{p}<0.05$ compared to GG group

Table 2: The association of klotho genotypes with patient survival

\begin{tabular}{lcccc}
\hline & \multicolumn{2}{c}{ Promoter G395A } & \multicolumn{2}{c}{ Exon 4 C1818T } \\
\cline { 2 - 5 } & GG & GA+AA & CC & CT+TT \\
\hline Survivor (\%) & $666(99.3)$ & $294(97.4)$ & $635(98.4)$ & $325(99.1)$ \\
Non-survivor (\%) & $5(0.7)$ & $8(2.6)$ & $10(1.6)$ & $3(0.9)$ \\
$p$ value & \multicolumn{2}{c}{0.022} & \multicolumn{2}{c}{0.371} \\
\hline$p$ value was obtained by the Pearson Chi-squared test \\
\hline
\end{tabular}

comparison of renal survival, which was calculated by Kaplan-Meier methods with followup periods and cumulative incidence of case treated with dialysis, A allele carriers at G395A showed significant worse renal outcome compared to non-carriers ( $\mathrm{p}=0.04$, Figure 1 ).

Predictors of ESRD progression in IgA nephropathy

In the univariate analysis using binary logistic regression about the factors affecting ESRD progression defined as entrance into dialysis treatment, older age, history of HTN, higher diastolic pressure, HDL, uric acid, creatinine and proteinuria increased the risk. On the other hand, higher weight, hemoglobin, albumin, and bilirubin were related to decrease the risk (data were not shown). Multivariate analysis with significant factors of renal survival in univariate analysis was shown in Table 4 with adjusted odd ratios with their $95 \%$ CI values. 


\section{Kidney Blood Pressure Research}

Fig. 1. Kaplan-Meier survival curves for renal survival of IgAN patients according to genotypes of G395A.

Ko/Lee/Jeon et al.: The Role of Klotho Polymorphisms in IgA Nephropathy

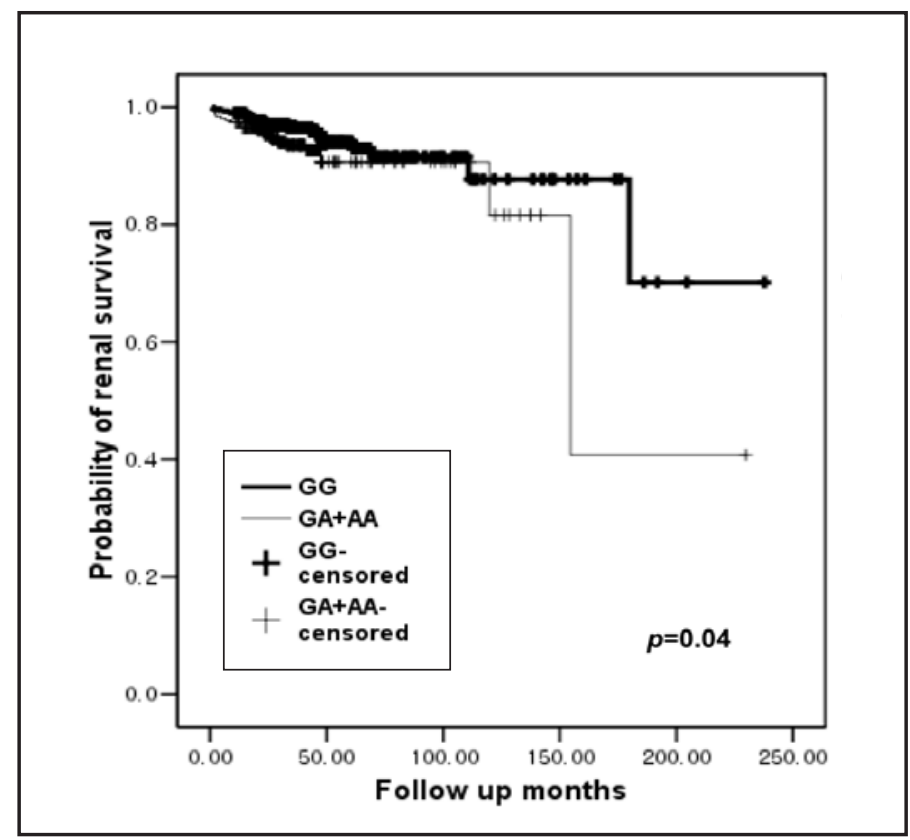

Table 3: The association of disease progression between genotypes

\begin{tabular}{lcccc}
\hline & \multicolumn{2}{c}{ Promoter G395A } & \multicolumn{2}{c}{ Exon 4 C1818T } \\
\cline { 2 - 5 } & GG & GA+AA & CC & CT+TT \\
\hline Non-ESRD (\%) & $633(95.3)$ & $277(92.6)$ & $600(94.2)$ & $310(94.8)$ \\
ESRD (\%) & $32(4.7)$ & $22(7.4)$ & $37(5.8)$ & $17(3.2)$ \\
$p$ value & \multicolumn{2}{c}{0.07} & \multicolumn{2}{c}{0.41} \\
\hline$p$ value was obtained by the Pearson Chi-squared test \\
\hline
\end{tabular}

Table 4: Multivariate analysis about the factors affecting renal survival

\begin{tabular}{lccc}
\hline Variables & \multicolumn{3}{c}{ Multivariate } \\
\cline { 2 - 4 } & Odd ratio & {$[95 \%$ C.I. $]$} & $p$ value \\
\hline Age & 1.035 & {$[0.985,1.088]$} & 0.177 \\
HTN & 4.395 & {$[0.714,27.009]$} & 0.110 \\
Weight & 0.890 & {$[0.830,0.955]$} & 0.052 \\
Diastolic BP & 0.973 & {$[0.911,1.040]$} & 0.425 \\
Hemoglobin & 1.208 & {$[0.755,1.931]$} & 0.430 \\
Albumin & 0.299 & {$[0.097,0.922]$} & 0.036 \\
Bilirubin & 0.542 & {$[0.057,4.563]$} & 0.548 \\
HDL & 1.017 & {$[0.985,1.051]$} & 0.302 \\
Uric acid & 1.296 & {$[1.014,1.658]$} & 0.039 \\
Creatinine & 1.720 & {$[1.172,2.525]$} & 0.006 \\
\hline
\end{tabular}

Data are expressed as the Odds ratio (OR) and its $95 \%$ confidence interval for each factor
It revealed that lower albumin and higher creatinine and uric acid were associated with ESRD progression treated with dialysis.

\section{Discussion}

We have demonstrated that genetic variation of single nucleotide polymorphism in klotho which was known to modulate the expression of klotho protein was associated with renal and patient survival of IgAN. It suggested that klotho might implicate the pathogenesis of progression of IgAN.

Although IgAN has been a concern with potential for ESRD, little has been known about influential factors on the prognosis of IgAN. Recently, genetic factor gained interest having prognostic value in IgAN, because

genetic variations for vasomotor activity and oxidative stress were reported the association with the prognosis of IgAN [15-16]. We hypothesized that klotho could be considered as one of candidate genes implicating in the pathogenesis of IgAN regarding the role of klotho on endothelial dysfunction and atherosclerosis [17-19]. Klotho was discovered as an anti- 


\section{Kidney Blood Pressure Research}

Kidney Blood Press Res 2012;36:191-199

\begin{tabular}{l|l}
\hline DOI: $10.1159 / 000343408$ & C 2012 S. Karger AG, Basel
\end{tabular}

Published online: November 11, 2012

www.karger.com/kbr

Ko/Lee/Jeon et al.: The Role of Klotho Polymorphisms in IgA Nephropathy

aging factor. Klotho mutant mice developed premature aging phenotype [1], whereas overexpression of klotho extended life span conversely [2]. Predominant expression of klotho in the kidney [23] was decreased in patients with chronic kidney injury and in the kidneys of diabetic nephropathy of rat [7,24], which suggested that klotho may be associated with the progression of chronic kidney disease. The role of klotho in kidney diseases was also demonstrated in recent studies that overexpression of klotho ameliorated endothelial dysfunction in diabetic nephropathy of rat [24] and conferred renal protection in glomerulonephritis and acute kidney injury of mice [5, 25].

Among more than 10 mutations with single nucleotide polymorphism (SNP) of klotho, genotypings of G395A in the promoter region and C1818T in exon 4 were conducted in this study, because other SNPs including KL-VS have been reported rare in asian people [2627]. The allele frequencies of $G$ and $A$ allele of G395A and $C$ and $T$ allele of C1818T were not different with the results of previous studies done in Korean population with normal renal function [27-28], which might suggest that SNPs of klotho in G395A and C1818T less likely affected the incidence of IgAN. However, the effect of klotho polymorphism on the incidence of IgAN should be demonstrated later by direct comparison with control group. Upon the comparison of baseline characteristics between genotypes, history of hypertension was higher in A allele carriers of G395A. It was consistent with some previous reports that SNPs of klotho affected the incidence of hypertension [22, 29]. The researchers assumed that endothelial dysfunction might induce the hypertension in patients with genotypes expressing klotho less such as A allele in G395A. But, the mechanism is not clear yet, and we don't believe that the history of hypertension itself influenced over the renal and patient survival of IgAN in our study, because measured blood pressure was not different between groups with similar amount of anti-hypertensive medication, and hypertension was not the significant factor for ESRD in multivariate analysis.

Despite relatively small number of mortality, there was a significant difference in patient survival between genotypes, and A allele carriers showed higher mortality. The role of genetic variation of klotho on mortality was also demonstrated in hemodialysis patients [21], which manifested similar result that the genotype with lower klotho expression showed higher mortality. Renal survival of IgAN was also different between genotypes. The probability of renal survival defined as expected duration from diagnosis of IgAN to entering into dialysis was significantly worse in A allele carriers at G395A. All these results indicated that klotho polymorphism played a role in renal and patients outcome of IgAN.

The role of klotho in chronic kidney disease has been explained at first related to the activity of fibroblast growth factor-23 (Fgf23) and klotho regulating calcium and phosphate homeostasis [30]. Recent studies demonstrated that klotho was associated with various kidney diseases including glomerulonephritis, ischemic kidney disease, hypertensive and diabetic nephropathy, and even polycystic kidney disease [5-7, 24, 31]. The underlying mechanisms are not clear, however, it has been shown that klotho involved with wide-ranging phenomena such as oxidative stress, apoptosis, inflammation, and fibrosis implicated in renal pathology [25, 32-34], and the interaction of klotho with renin-angiotensin system or mTOR signaling was suggested to modulate those processes [35-36]. Genetic variations of klotho could influence on the progression of chronic kidney disease through these mechanisms, and it was reflected in a report that SNPs of klotho affected the severity of non-diabetic ESRD [37] as in our study.

Beyond the effect on renal function, the extensive function of klotho also could be associated with the progression of cardiovascular disease [38] and uremic atherosclerosis [19] in CKD patients. Although the cause of death was not checked exactly, it might explain the higher mortality in less active klotho carriers in our study and previous study done in hemodialysis patients [21].

Though this is the first remark on the association between klotho polymorphism and the renal and patient survival of IgAN to our knowledge, there were several limitations. First, the exact causes of death were not specified, and it hindered the speculation of the role of klotho in patient survival of IgAN. Second, the level of klotho was not measured so that the inferior 


\section{Kidney \\ Blood Pressure Research}

genotypes for klotho expression were not verified directly. Third, all the genotypes of klotho polymorphisms were not examined in this study, because the amount of available samples was not enough. Fourth, genotypes of klotho were not included as a significant predictor for ESRD in multivariate analysis. However, the total number of ESRD patients entering into dialysis was relatively small for the conclusion, and the effect of genotypes on renal survival was demonstrated with other method.

\section{Conclusion}

The genotypes expressing klotho less may be associated with poor patient survival and renal outcome in IgAN.

\section{Conflict of Interests}

The authors of this manuscript state that they have no conflict of interests.

\section{Acknowledgement}

G.J. Ko and Y.J. Kwon were supported by Korea University (K1030581 and KUGH11063001). The authors acknowledge the valuable contribution of The Progressive Renal disease and Medical Informatics and gEnomics Research (PREMIER) members: (Cheju National University Hospital (Eun Hee Jang), Chonbuk National University Medical School (Won Kim), Chonnam National University Medical School (Nam Ho Kim, Woo Kyun Bae), Chungbuk National University College of Medicine (Hye Young Kim), Chungnam National University College of Medicine (Young-Tai Shin, Kang Wook Lee, Ki Ryang Na), Daegu Catholic University Medical Center (Ki Sung Ahn), Dankook University Hospital (Jong Tae Cho, Eun Kyeong Lee), Dong-A University College of Medicine (Ki Hyun Kim, WonSuk An, Seong Eun Kim), Ewha Womans University School of Medicine ( Choi Gyu Bog, Seung-Jung Kim), Gachon University of Medicine and Science (Woo Kyung Chung, Hyun Hee Lee, Jaeseok Yang, Sejoong Kim), Gyeongsang National University Hospital (Se-Ho Chang), Hallym University College of Medicine (Jung Woo Noh, Young Ki Lee, Seong Gyun Kim, Jieun Oh, Young Rim Song), Inha University College of Medicine (Moon Jae Kim, Seoung Woo Lee), Inje University College of Medicine (Yeong Hoon Kim, Won Do Park), Keimyung University School of Medicine (Hyun Chul Kim, Sung Bae Park), Konkuk University School of Medicine (Kyo-Soon Kim), Korea University Anam Hospital (Won Yong Cho, Hyoung Kyu Kim, Sang-Kyung Jo), Korea University Ansan Hospital (Cha Dae Ryong, Kang Young Sun), Korea University Guro Hospital (Young Joo Kwon), Kyungpook National University School of Medicine (Yong Lim Kim, Sun-Hee Park, Chan-Duck Kim), Pochon CHA University College of Medicine (Dong Ho Yang), Pusan National University School of Medicine (Ihm Soo Kwak, Soo Bong Lee, Dong Won Lee, Sang Heon Song, Eun Young Seoung), Seoul Medical center (Su-Jin Yoon), Seoul National University Bundang Hospital (Dong-Wan Chae, Ki Young Na, Ho Jun Chin), Seoul National University College of Medicine Boramae Medical Center ( Chun Soo Lim, Yoon Kyu Oh), Seoul National University Hospital (Kook Hwan Oh, Kwon Wook Joo, Yon-Su Kim, Curie Ahn, Jin Suk Han, Suhnggwon Kim), Seoul National University Hospital Clinical Institute (Hyung Jin Yoon), Sungkyunkwan University School of Medicine (Kyu-Beck Lee), Sungkyunkwan University, School of Medicine Samsung Medical Center (Yoon Goo Kim, Jung Eun Lee), Ulsan University College of Medicine, Asan Medical Center (Sang Koo Lee), Yeungnam University College of Medicine (Jun-Young Do, Jong-Won Park, Kyung-Woo Yoon). 


\section{Kidney \\ Blood Pressure Research}

Kidney Blood Press Res 2012;36:191-199

\begin{tabular}{l|l}
\hline DOI: $10.1159 / 000343408$ & (c) 2012 S. Karger AG, Basel
\end{tabular}

Published online: November 11, 2012

www.karger.com/kbr

Ko/Lee/Jeon et al.: The Role of Klotho Polymorphisms in IgA Nephropathy

\section{References}

1 Kuro-o M, Matsumura Y, Aizawa H, Kawaguchi H, Suga T, Utsugi T, Ohyama Y, Kurabayashi M, Kaname T, Kume E, Iwasaki H, Iida A, Shiraki-Iida T, Nishikawa S, Nagai R, Nabeshima YI: Mutation of the mouse klotho gene leads to a syndrome resembling ageing. Nature 1997;390:45-51.

-2 Kurosu H, Yamamoto M, Clark JD, Pastor JV, Nandi A, Gurnani P, McGuinness OP, Chikuda H, Yamaguchi M, Kawaguchi H, Shimomura I, Takayama Y, Herz J, Kahn CR, Rosenblatt KP, Kuro-o M: Suppression of aging in mice by the hormone klotho. Science 2005;309:1829-1833.

-3 Arking DE, Krebsova A, Macek M, Sr., Macek M, Jr., Arking A, Mian IS, Fried L, Hamosh A, Dey S, McIntosh I, Dietz HC: Association of human aging with a functional variant of klotho. Proc Natl Acad Sci U S A 2002;99:856-861.

4 Matsumura Y, Aizawa H, Shiraki-Iida T, Nagai R, Kuro-o M, Nabeshima Y: Identification of the human klotho gene and its two transcripts encoding membrane and secreted klotho protein. Biochem Biophys Res Commun 1998;242:626-630.

5 Haruna Y, Kashihara N, Satoh M, Tomita N, Namikoshi T, Sasaki T, Fujimori T, Xie P, Kanwar YS: Amelioration of progressive renal injury by genetic manipulation of klotho gene. Proc Natl Acad Sci U S A 2007;104:2331-2336.

-6 Sugiura H, Yoshida T, Mitobe M, Yoshida S, Shiohira S, Nitta K, Tsuchiya K: Klotho reduces apoptosis in experimental ischaemic acute kidney injury via hsp-70. Nephrol Dial Transplant 2010;25:60-68.

7 Koh N, Fujimori T, Nishiguchi S, Tamori A, Shiomi S, Nakatani T, Sugimura K, Kishimoto T, Kinoshita S, Kuroki T, Nabeshima Y: Severely reduced production of klotho in human chronic renal failure kidney. Biochem Biophys Res Commun 2001;280:1015-1020.

8 Donadio JV, Grande JP: Iga nephropathy. N Engl J Med 2002;347:738-748.

-9 Koyama A, Igarashi M, Kobayashi M: Natural history and risk factors for immunoglobulin a nephropathy in japan. Research group on progressive renal diseases. Am J Kidney Dis 1997;29:526-532.

10 Geddes CC, Rauta V, Gronhagen-Riska C, Bartosik LP, Jardine AG, Ibels LS, Pei Y, Cattran DC: A tricontinental view of iga nephropathy. Nephrol Dial Transplant 2003;18:1541-1548.

11 Lee HS, Choi Y, Lee JS, Yu BH, Koh HI: Ultrastructural changes in iga nephropathy in relation to histologic and clinical data. Kidney Int 1989;35:880-886.

-12 Coppo R, Amore A, Peruzzi L, Vergano L, Camilla R: Innate immunity and iga nephropathy. J Nephrol 2010;23:626-632.

-13 Chen HC, Tomino Y, Yaguchi Y, Fukui M, Yokoyama K, Watanabe A, Koide H: Oxidative metabolism of polymorphonuclear leukocytes (pmn) in patients with iga nephropathy. J Clin Lab Anal 1992;6:35-39.

14 del Castillo D, Raij L: Pathophysiology of the interaction between mesangium and endothelium. Contrib Nephrol 1995;111:29-37.

15 Chin HJ, Cho HJ, Lee TW, Na KY, Yoon HJ, Chae DW, Kim S, Jeon US, Do JY, Park JW, Yoon KW, Shin YT, Lee KW, Na KR, Cha DR, Kang YS: The heme oxygenase-1 genotype is a risk factor to renal impairment of iga nephropathy at diagnosis, which is a strong predictor of mortality. J Korean Med Sci 2009;24:S30-S37.

16 Yoon HJ, Chin HJ, Na KY, Chae DW, Kim S, Jeon US, Chung WK, Lee HH, Yang J, Kwon YJ, Kim HC, Park SB, Kim HY, Lee TW: Association of angiotensin II type 2 receptor gene a1818t polymorphism with progression of immunoglobulin a nephropathy in korean patients. J Korean Med Sci 2009;24:S38-S43.

17 Saito Y, Yamagishi T, Nakamura T, Ohyama Y, Aizawa H, Suga T, Matsumura Y, Masuda H, Kurabayashi M, Kuro-o M, Nabeshima Y, Nagai R: Klotho protein protects against endothelial dysfunction. Biochem Biophys Res Commun 1998;248:324-329.

18 Hu MC, Shi M, Zhang J, Quinones H, Griffith C, Kuro-o M, Moe OW: Klotho deficiency causes vascular calcification in chronic kidney disease. J Am Soc Nephrol 2011;22:124-136.

-19 Ichikawa S, Imel EA, Kreiter ML, Yu X, Mackenzie DS, Sorenson AH, Goetz R, Mohammadi M, White KE, Econs MJ: A homozygous missense mutation in human klotho causes severe tumoral calcinosis. J Musculoskelet Neuronal Interact 2007;7:318-319.

20 Kim Y, Jeong SJ, Lee HS, Kim EJ, Song YR, Kim SG, Oh JE, Lee YK, Seo JW, Yoon JW, Koo JR, Kim HJ, Noh JW, Park SH: Polymorphism in the promoter region of the klotho gene (g-395a) is associated with early dysfunction in vascular access in hemodialysis patients. Korean J Intern Med 2008;23:201-207. 


\section{Kidney \\ Blood Pressure Research}

Kidney Blood Press Res 2012;36:191-199

\begin{tabular}{l|l}
\hline DOI: $10.1159 / 000343408$ & C 2012 S. Karger AG, Basel
\end{tabular}

Published online: November 11, 2012

www.karger.com/kbr

-21 Friedman DJ, Afkarian M, Tamez H, Bhan I, Isakova T, Wolf M, Ankers E, Ye J, Tonelli M, Zoccali C, Kuro-o M, Moe O, Karumanchi SA, Thadhani R: Klotho variants and chronic hemodialysis mortality. J Bone Miner Res 2009;24:1847-1855.

-22 Wang HL, Xu Q Wang Z, Zhang YH, Si LY, Li XJ, Yang QH, Xiao H: A potential regulatory single nucleotide polymorphism in the promoter of the klotho gene may be associated with essential hypertension in the chinese han population. Clin Chim Acta 2010;411:386-390.

-23 Chang Q, Hoefs S, van der Kemp AW, Topala CN, Bindels RJ, Hoenderop JG: The beta-glucuronidase klotho hydrolyzes and activates the trpv5 channel. Science 2005;310:490-493.

24 Cheng MF, Chen LJ, Cheng JT: Decrease of klotho in the kidney of streptozotocin-induced diabetic rats. J Biomed Biotechnol 2010;513853.

25 Sugiura H, Yoshida T, Tsuchiya K, Mitobe M, Nishimura S, Shirota S, Akiba T, Nihei H: Klotho reduces apoptosis in experimental ischaemic acute renal failure. Nephrol Dial Transplant 2005;20:2636-2645.

-26 Shimoyama Y, Taki K, Mitsuda Y, Tsuruta Y, Hamajima N, Niwa T: Klotho gene polymorphisms g-395a and c1818t are associated with low-density lipoprotein cholesterol and uric acid in japanese hemodialysis patients. Am J Nephrol 2009;30:383-388.

27 Rhee EJ, Oh KW, Lee WY, Kim SY, Jung CH, Kim BJ, Sung KC, Kim BS, Kang JH, Lee MH, Kim SW, Park JR: The differential effects of age on the association of klotho gene polymorphisms with coronary artery disease. Metabolism 2006;55:1344-1351.

-28 Jo SH, Kim SG, Choi YJ, Joo NR, Cho GY, Choi SR, Kim EJ, Kim HS, Kim HJ, Rhim CY: Klotho gene polymorphism is associated with coronary artery stenosis but not with coronary calcification in a korean population. Int Heart J 2009;50:23-32.

29 Shimoyama Y, Nishio K, Hamajima N, Niwa T: Klotho gene polymorphisms g-395a and c1818t are associated with lipid and glucose metabolism, bone mineral density and systolic blood pressure in japanese healthy subjects. Clin Chim Acta 2009;406:134-138.

-30 Kurosu H, Ogawa Y, Miyoshi M, Yamamoto M, Nandi A, Rosenblatt KP, Baum MG, Schiavi S, Hu MC, Moe OW, Kuro-o M: Regulation of fibroblast growth factor-23 signaling by klotho. J Biol Chem 2006;281:6120-6123.

-31 Pavik I, Jaeger P, Ebner L, Poster D, Krauer F, Kistler AD, Rentsch K, Andreisek G, Wagner CA, Devuyst O, Wüthrich RP, Schmid C, Serra AL: Soluble klotho and autosomal dominant polycystic kidney disease. Clin J Am Soc Nephrol 2012;7:248-257.

32 Zuo Z, Lei H, Wang X, Wang Y, Sonntag W, Sun Z: Aging-related kidney damage is associated with a decrease in klotho expression and an increase in superoxide production. Age (Dordr) 2011;33:261-274.

33 Zhao Y, Banerjee S, Dey N, LeJeune WS, Sarkar PS, Brobey R, Rosenblatt KP, Tilton RG, Choudhary S: Klotho depletion contributes to increased inflammation in kidney of the $\mathrm{db} / \mathrm{db}$ mouse model of diabetes via RelA (serine)536 phosphorylation. Diabetes 2011;60:1907-1916.

-34 Doi S, Zou Y, Togao O, Pastor JV, John GB, Wang L, Shiizaki K, Gotschall R, Schiavi S, Yorioka N, Takahashi M, Boothman DA, Kuro-o M: Klotho inhibits transforming growth factor-beta1 (TGF-beta1) signaling and suppresses renal fibrosis and cancer metastasis in mice. J Biol Chem 2011;286:8655-8665.

-35 Tang R, Zhou QL, Ao X, Peng WS, Veeraragoo P, Tang TF: Fosinopril and losartan regulate klotho gene and nicotinamide adenine dinucleotide phosphate oxidase expression in kidneys of spontaneously hypertensive rats. Kidney Blood Press Res 2011;34:350-357.

-36 Tataranni T, Biondi G, Cariello M, Mangino M, Colucci G, Rutigliano M, Ditonno P, Schena FP, Gesualdo L, Grandaliano G: Rapamycin-induced hypophosphatemia and insulin resistance are associated with mTORC2 activation and klotho expression. Am J Transplant 2011;11:1656-1664.

-37 Bostrom MA, Hicks PJ, Lu L, Langefeld CD, Freedman BI, Bowden DW: Association of polymorphisms in the klotho gene with severity of non-diabetic ESRD in African Americans. Nephrol Dial Transplant 2010;25:3348-3355.

38 Kusano E: Mechanism by which chronic kidney disease causes cardiovascular disease and the measures to manage this phenomenon. Clin Exp Nephrol 2011;15:627-633. 